\title{
O GILDO QUE CONHECI
}

Marcelo Ridenti

Era sabido que Gildo poderia partir a qualquer momento, dados seus problemas de saúde. Mas ele já havia escapado de tantas, e lidava tão bem com isso, que até parecia imortal. E não deixa de ser, pelo menos enquanto vivermos, às muitas pessoas que o queriam bem. Agora mesmo, tenho a impressão de que ele está a meu lado, com seu jeito acolhedor e amigo. Era muito gostoso encontrar com ele e falar de projetos, pois, invariavelmente, dava uma opinião lúcida e um incentivo caloroso. Ele não precisava diminuir os outros para se valorizar. Gostava de ver os colegas e amigos realizarem seus projetos. Um bom companheiro, no sentido forte do termo.

A vida afasta e aproxima as pessoas, geralmente em função de determinadas circunstâncias, interesses comuns, trabalho, crenças ou sabe-se lá que mistério. Conheci Gildo Marçal Brandão numa reunião da Anpocs, quase perdida na memória, em Águas de São Pedro, na segunda metade dos anos 1980. Nossa amizade seria marcada pela ligação com essa instituição, em dois momentos. O primeiro iria até 1993, no Grupo de Trabalho (GT) Partidos e Movimentos de 
Esquerda. O segundo, mais intenso, em nossa gestão à frente da entidade por quatro anos, a partir de outubro de 2004.

Ninguém que participou se esquece dos acalorados debates com os colegas estudiosos da esquerda brasileira que integravam nosso GT, ao qual me integrei em 1985, e Gildo um ou dois anos depois. Faziam parte intelectuais, como Marco Aurélio Garcia, João Quartim de Moraes, Daniel Aarão Reis, Carlos Nelson Coutinho, Celso Frederico, Ricardo Antunes, João Roberto Martins, Michel Zaidan, Osvaldo Coggiola, Rubens Pinto Lyra, Antônio Albino Rubim, Sílvio Frank Alem, entre outros. Naquele tempo, Gildo preparava sua tese sobre o Partido Comunista e eu, a minha sobre a esquerda armada, podendo nos beneficiar das críticas do grupo. Ele era professor da PUC na ocasião, indo logo em seguida para a USP, como cientista político. Eu era mais jovem e começava a carreira de sociólogo na Universidade de Londrina, antes de ir para a Unesp de Ara30 raquara e, mais tarde, para a Unicamp.

Um belo dia, em 1994, a direção da Anpocs não selecionou o programa do GT para seu encontro anual (a seleção passava a ocorrer periodicamente, com o objetivo de não cristalizar grupos e de renovar a instituição). Estavam em baixa no mercado acadêmico os estudos como aqueles realizados pelo nosso GT, no contexto mais amplo da derrota do chamado "socialismo real" - mesmo que quase ninguém do GT se identificasse com ele, embora fosse um dos grupos mais ativos da entidade. Provavelmente, o GT poderia ser selecionado em anos seguintes, mas a maioria do grupo resolveu dar as costas à Anpocs. Poucos, como Gildo e eu, pensavam que teria valido a pena insistir, sabendo que a roda do tempo e da fortuna não para. Só não imaginávamos que ela virasse tanto, a ponto de nos conduzir à direção da entidade uma década depois.

No período que separa o encerramento das atividades do GT e nossa administração na Anpocs, conversei com o 
Gildo esporadicamente. O encontro mais marcante foi em Pittsburgh, onde passamos um dia juntos em outubro de 1995. Ele morava lá com a Simone e os filhos para realizar um pós-doutorado, enquanto eu estava de passagem para um seminário.

Tínhamos amigos comuns, como Elide Rugai Bastos, minha colega de departamento na Unicamp. No começo dos anos 2000, ela ocupava a secretaria adjunta da Anpocs. A secretária executiva era Maria Arminda Nascimento Arruda, também nossa amiga. Até hoje não entendi bem como se deu o processo de sucessão, exceto que houve algum tipo de impasse que levou a convocar colegas menos enfronhados no dia a dia da entidade, que fossem ao mesmo tempo confiáveis e em condições de levar adiante o trabalho de abertura que a gestão anterior iniciara.

Um acordo definiu a candidatura de Gabriel Cohn à presidência da Anpocs, de Gildo à secretaria adjunta, além da minha à secretaria executiva. Pronto, estava dada a circunstância objetiva que me aproximaria de Gildo novamente. A presença de Gabriel na presidência era fundamental para legitimar nossa chapa, num momento em que se antevia certa dificuldade para chegar ao consenso que normalmente caracteriza as sucessões na Anpocs, e que foi garantido em grande parte devido ao reconhecimento da comunidade de cientistas sociais pelo trabalho de Gabriel Cohn, colega de departamento de Gildo, e que havia sido meu professor.

Trabalhamos juntos por dois anos, os três afinados. Eu brincava com o Gildo, dizendo que me sentia parceiro de Don Quixote e Sancho Pança, equilibrando-me entre os dois. Ele ria e não levava a mal, pois sabia que eu admiro muito tanto o personagem Sancho como o Quixote, ambos presentes em todos nós.

Gildo também tinha seu lado quixotesco, como não? Ele se revelava na vida pessoal pela enorme vontade e ale- 
gria de viver, não se deixava acabrunhar pelos limites de saúde. Política e academicamente, gostava de medir cada passo para que não fosse maior que a perna, avaliar cada medida, calcular todos os prós e contras, as repercussões, os custos e benefícios de cada ação. Mas gostava de pensar grande, por exemplo, projetava que nossa gestão tinha de ser marcante, a partir de uma receita simples: abrigar todos os grupos, temas e correntes de pensamento, não excluir ninguém por qualquer tipo de preconceito intelectual, responder ao crescimento e às mudanças nas ciências sociais brasileiras, sem, contudo, perder a marca de excelência acadêmica da Anpocs, em geral, e da Revista Brasileira de Ciências Sociais (RBCS), em particular; afinal, ele seria seu editor. Não me sinto à vontade para elogiar a atuação do Gildo na Anpocs, pois fizemos o trabalho tão integradamente que isso seria constrangedor.

Nossa responsabilidade ao assumir a direção da Anpocs era grande, quer porque precisávamos manter a qualidade da gestão anterior, quer porque havia uma situação de impasse, quer porque ambos éramos identificados como de esquerda, na tradição intelectual marxista. Muita gente pensa que a esquerda é boa para criticar e ruim para administrar, seria preciso mostrar que isso não passa de um chavão. Para mim, esse último aspecto pesava menos, pois me integrei a essa tradição nos bancos do curso de Ciências Sociais da USP no fim dos anos 1970.

A questão era mais complicada para Gildo, pois ele tivera uma militância intelectual expressiva fora da academia, no Partido Comunista. Sua atuação marcou época no jornal Voz da Unidade e na revista Temas em Ciências Humanas. Ou seja, além de ser identificado como herdeiro de uma tradição intelectual considerada por muitos ultrapassada, ele tinha de se debater com a dificuldade de aceitação no meio acadêmico, devido a seu passado comunista, que fazia dele, para alguns, um estranho no ninho. 
Mais de uma vez Gildo me disse que via em jovens e bons estudantes alguma propensão para aproximar-se da tradição marxista de pensamento, mas preferiam não fazê-lo, temendo estreitar os horizontes de carreira. Eu ponderava que talvez isso fosse mais sensível no cotidiano dele na USP do que no meu na Unicamp. Ademais, nós dois éramos contraexemplos. Mas é inegável que o estigma existe.

Lembrando os tempos do PCB, Gildo me contava como era cruel a luta política interna, que levava à ruptura de laços pessoais, não raro por questões que, atualmente, parecem pequenas. Dizia também que, hoje, poderíamos ser mais úteis como intelectuais independentes do que organizados em algum partido. Desprezava o marxismo vulgar. Irritava-se com o que lhe parecia esquerdismo irresponsável. Não achava produtivo fazer mesas e seminários acadêmicos compostos por intelectuais com pensamento semelhante. Adorava o debate e a pluralidade de opiniões. Buscava ser isento e dar vez e voz a todos.

Gildo tinha clareza de quem eram seus adversários no meio universitário; não obstante, tratava-os com respeito e cortesia, sem boicotá-los. Não sei se jogava xadrez, mas na vida acadêmica sabia avaliar os movimentos de todas as peças, posicionando as suas da melhor forma no centro do tabuleiro. Era mais afirmativo que negativo, democrático, talvez um exemplo vivo do que chamou em seus trabalhos de "esquerda positiva", recuperando o termo de San Tiago Dantas do começo dos anos 1960, no sentido de que é preciso ter proposições afirmativas para atuar dentro da ordem, não apenas recusá-la.

Ainda não avaliei em que medida concordo com as análises que Gildo desenvolveu em seus trabalhos. Perguntome, por exemplo, até que ponto pode-se fazer um corte nítido entre uma esquerda positiva e outra negativa; ademais, positiva e negativa em relação a quê? Em todo caso, gosto de sua formulação de que o PCB esboçou a "cons- 
trução de uma (contra) elite de corte nacional". ${ }^{1}$ Tínhamos afinidades, dentro da mesma família intelectual e política, mas também diferenças, até geracionais. Claro que sempre apostamos nas afinidades, condição para qualquer trabalho coletivo.

Voltando a nosso cotidiano na Anpocs, as coisas caminharam bem na primeira gestão e viriam a continuar assim na segunda, agora com Ruben Oliven como presidente. Rapidamente nos tornamos amigos e irmanados nos mesmos objetivos. Quando Ruben passava por São Paulo, ou em Caxambu, conversávamos horas e tomávamos algum vinho que o Gildo escolhia, por vezes na casa dele, sempre acolhedora. Falávamos dos planos para a Anpocs, da busca de financiamento (que senso prático e de iniciativa o Ruben tem!), e ainda de outras coisas boas da vida. No fim da gestão, organizamos um livro cujo espírito expressa nossas convicções democráticas comuns. ${ }^{2}$

Gildo estava cada vez mais à vontade. Ano a ano, na noite do último dia do encontro da Anpocs, ele podia ser visto de sorriso aberto no Hotel Glória em Caxambu, comemorando o que considerava ser um sucesso. Ele sempre me dizia à beira da piscina: "Ótimo!". Eu adorava, mas respondia que ele era suspeito, que ainda tínhamos muito trabalho pela frente. Depois de quatro anos de diretoria e à frente da RBCS, parecia sentir-se academicamente reconhecido. A coordenação de um projeto temático apoiado pela Fapesp e seu concurso para professor titular, marcado para março, completariam o quadro. Não dava mais para ser considerado um estranho no ninho.

A repercussão pública da morte de Gildo foi significativa. Ouvi comentários a respeito no rádio, quando me dirigia

\footnotetext{
${ }^{1}$ BRANDÃO, G. M., A esquerda positiva: as duas almas do Partido Comunista, 1920/1964. São Paulo: Hucitec, 1997, p. 234.

2 OLIVEN, R. G.; BRANDÃO, G. M.; RIDENTI, M. (org.). A Constituição de 1988 na vida brasileira. São Paulo: Hucitec/Anpocs, 2008.
} 
ao velório, li a notícia no jornal, sem procurar. Ouvi lamentos de tantos amigos e colegas. Será que teria sido assim para algum acadêmico sisudo, ensimesmado, que menospreza os outros, pensando apenas na própria carreira, por mais brilhante que seja? Gildo foi uma grande pessoa, um intelectual expressivo e um homem consciente da dimensão pública de sua atividade, fosse atuando no PCB ou, mais tarde, na Universidade.

Adeus, Gildo. Não vamos mais ouvir a pronúncia inesquecível da palavra que você gostava de repetir com sinceridade e empolgação contagiante, ao receber uma boa notícia ou proposta: "ótimo!"

Companheiro Gildo, seu coração era grande e sua alma nunca foi pequena. Viver valeu a pena! 